\title{
POLLUTION AND POLLUTION CONTROL IN THE THIRD WORLD
}

\author{
J. STOCK AND Z. MARIN \\ Centro de Investigaciones de Astronomia, Apdo. 264, Merida, Venezuela
}

\begin{abstract}
In developing countries in Latin America, Asia, and Africa, light pollution takes a particular aspect due to the social and economical situation. The official reluctance to solve unpopular problems combined with a generalized ignorance create a hostile climate for any campaign in favor of astronomical observatories or amateur associations. The tropical climate makes most energy savings measures unnecessary. Obsolete industrial installations make the application of particle output control difficult or impossible. The most important contribution to air pollution, however, comes from forest fires, some of them as a cheap clearing method, others as an expressions of political discontent. To this must be added that most countries do not have yet a legislature which would permit the imposition of pollution control.
\end{abstract}

Light pollution depends on two factors: light emission and scattering particle abundance. The first is a strictly local problem; the other depends not only on local contributors but also on the global abundance and its distribution. The latter has recently become rather important.

The terminology "Third World" is not a very happy one. There is only one world and all of us are part of it. To talk about "developing" or "underdeveloped" parts of the world is discriminating. Sometimes the terminology is understood in a political sense, referring to those countries which have not committed themselves to either of the two principal ideologies. No matter which classification you wish to apply, you will find a concentration of the "Third World" towards the tropics.

The economy of the countries involved depends either on agriculture, and thus is vulnerable to the global climate changes, or on the extraction of a single natural reserve, thus vulnerable to world market fluctuations and political confrontations. In all cases, they depend heavily on foreign technology.

Not too long ago, the non-industrialized countries marked dark areas on the nocturnal image of the earth. This is rapidly changing. Electricity is penetrating the most remote areas, even if there will never be reasonable commercial return. It is more than human that after a long history in darkness, people happily brighten their world far beyond what is necessary. The states around the Persian Gulf are incredibly bright spots on the nocturnal map we have before us, and South America is about to follow the pattern. To this we have to add that population in the third world grows more rapidly than elsewhere. 
The production of scattering particles shows more complicated aspects. Concentrations of population and industries are scarce, but do exist. More important is the smoke production. The burning of forests for clearing purposes is traditional, just as the burning of garbage and weeds. The increasing demand of agricultural production means just so much more smoke. Recently, however, something new came into the picture, namely the intentional burning of forests as an expression of political dissatisfaction. This activity is most noticeable (because it is more effective) during dry seasons, which coincide with the best astronomical observing season.

At this point, I have to mention a very serious matter. We all know the disastrous effect of the particles emitted by combustion engines. In this country as well as in Europe, engines have been designed for a minimum output of contaminants, and exhaust control is common practice (also for industrial installations). Additives to the gasoline are no longer required. However, automobiles delivered to the third world are in most cases not based on this technology; thus their operation still requires additives. Add to this the fact that automobiles and spare parts are extremely expensive due to the unfavorable rate of exchange. This means that oilburning cars, trucks and buses are a common feature, and the respective owners cannot afford the required repairs. Industrial installations, many of them obsolete, are in a similar situation. the measures to be taken by the authorities appear obvious, and in many cases do exist on paper. They cannot be enforced because they are economically unbearable, and hence unpopular.

Measures to control light output are equally unpopular, even around the observatories. Part of the reason is the generalized ignorance, but that is not all of it. A good example is our observatory in Venezuela. No significant illumination existed in its surroundings where the site was located 26 years ago because there was no electricity. The city of Merida, at a distance of 40 kilometers, then had 30,000 inhabitants. Now it has grown to 145,000 people. The electrical power supplied to the observatory also serves the nearby villages. Public illumination has been installed everywhere. We requested lampshades, which would at least avoid the direct illumination of the sky. The authorities in principle approved the measure; however, only under the condition that the observatory pay the cost of the shades, their installation and their maintenance. This would be a large item in the observatory's budget, and out of the question.

We know the origin of scattering particles in the atmosphere. We also know that they will eventually form condensation nuclei and return to the ground by precipitation. However, many of them stay long enough in the atmosphere to be carried far away from their region of origin. Thus they can and do affect areas with little or no production of contaminants as well. A good example is the tropics. Until recently the tropical zone was a weather system all of its own, with little air exchange with the neighboring temperature zones. This has maintained a clean and clear air over many years at our observatory in Venezuela, interrupted only occasionally by smoke from nearby forest fires. Local origin of smoke is also evidenced by its non-uniform and highly structured distribution. During the past years we have had situations of uniformly distributed scattering particles on several occasions, lasting each time for two to five days. This year we have observed for the first time a major event of this type. Highly contaminated air penetrated the tropics in March and lasted for at least all month. At that time I left Venezuela and thus cannot tell how much longer it persisted. 
To summarize, the economical and the political situation of the third world makes pollution control very difficult. At the same time, the preservation of observing conditions at their own sites is not entirely up to them.

P.S. Recently the President of Venezuela signed a Resolution declaring the surroundings of the Observatory a zone to be protected from light and air pollution. 